\title{
Tinjauan Kejadian Keruntuhan Jembatan Kali Sapi Lama Berdasarkan Analisis Debit Kala Ulang
}

\author{
Review of Kali Sapi Old Bridge Collaps based on Return Period Discharge \\ Analisys \\ Teguh Marhendi ${ }^{*}$, Wahlul Sodikin ${ }^{2}$ \\ 1,2)Program Studi Teknik Sipil, Fakultas Teknik dan Sains \\ Universitas Muhammadiyah Purwokerto \\ *email: tmarhendi@gmail.com, teguhmarhendi@ump.ac.id
}

\begin{abstract}
ABSTRAK
Jembatan Kali Sapi yang terletak di Desa Karanganyar

Histori Artikel:

Diajukan:

$21 / 03 / 2018$

Diterima:

$26 / 10 / 2018$

Diterbitkan:

$17 / 11 / 2018$ Kecamatan Purwanegara, Banjarnegara, mengalami keruntuhan pada 24 Oktober 2010. Besar debit tercatat saat kejadian berlangsung adalah $50,15 \mathrm{~m}^{3} / \mathrm{dtk}$ dengan curah hujan tercatat mencapai $105 \mathrm{~mm}$. Tujuan penelitian ini adalah untuk mengkaji kejadian keruntuhan jembatan Kali Sapi berdasarkan debit banjir kala ulang Sungai Kali Sapi. Perhitungan debit Banjir kala ulang pada penelitian ini menggunakan Metode Haspers, Metode Der Weduwen dan Metode Melchior. Hasil penelitian menunjukkan besar debit banjir kala ulang menggunakan Metode Haspers $Q_{25}=237,597$ $\mathrm{m}^{3} / \mathrm{dtk}, \mathrm{Q}_{50}=260,055 \mathrm{~m}^{3} / \mathrm{dtk}$ dan $\mathrm{Q}_{100}=282,347 \mathrm{~m}^{3} / \mathrm{dtk}$. Pada Metode Weduwen $\mathrm{Q}_{25}=274,520 \mathrm{~m}^{3} / \mathrm{dtk}, \mathrm{Q}_{50}=300,468 \mathrm{~m}^{3} / \mathrm{dtk}$ dan $\mathrm{Q}_{100}=326,225 \mathrm{~m}^{3} / \mathrm{dtk}$. Metode Melchior $\mathrm{Q}_{25}=304,837 \mathrm{~m}^{3} / \mathrm{dtk}, \mathrm{Q}_{50}=$ $333,651 \mathrm{~m}^{3} / \mathrm{dtk}$ dan $\mathrm{Q}_{100}=362,251 \mathrm{~m}^{3} / \mathrm{dtk}$. Selanjutnya berdasarkan umur rencana, jembatan Kali Sapi didesain dengan umur rencana 50 tahun. Berdasarkan metode Haspers, debit pada kala ulang 50 tahuan adalah $260,055 \mathrm{~m}^{3} / \mathrm{dtk}$. Jika dibandingkan dengan besaran debit banjir saat kejadiaan ( $\left.50,15 \mathrm{~m}^{3} / \mathrm{dtk}\right)$, maka keruntuhan jembatan bukan disebabkan oleh besaran debit banjir.
\end{abstract}

Kata Kunci: keruntuhan jembatan, debit kala ulang, Sungai Kali Sapi

\begin{abstract}
On Sunday, October 24, 2010 Kali Sapi Bridge located in Karanganyar Village, Purwanegara Sub District, Banjarnegara, has collapsed. The amount of flood discharge recorded during the event was $50.15 \mathrm{~m} 3$ / s with the recorded rainfall of $105 \mathrm{~mm}$. The aim of this study was to review the occurrence of colapse Kali Sapi bridge based on flood discharge Kali Sapi River. Calculation of debit Flood of return period in this research using Haspers Method, Der Weduwen Method and Melchior Method. The results of research showed that the flood discharge was Haspers Method Q25 $=237,597 \mathrm{~m} 3 / \mathrm{s}$, $\mathrm{Q} 50=260,055 \mathrm{~m} 3 / \mathrm{s}$ and Q100 $=282,347 \mathrm{~m} 3 / \mathrm{s}$. In the Weduwen Method Q25 $=274,520 \mathrm{~m} 3 / \mathrm{s}$, $\mathrm{Q} 50=300.468 \mathrm{~m} 3 / \mathrm{s}$ and $\mathrm{Q} 100=326.225 \mathrm{~m} 3 / \mathrm{s}$. Melchior method Q25 $=304,837 \mathrm{~m} 3 / \mathrm{s}, \mathrm{Q} 50=$ $333,651 \mathrm{~m} 3 / \mathrm{s}$ and Q100 $=362,251 \mathrm{~m} 3 / \mathrm{s}$. Furthermore, based on the life time, the Kali Sapi bridge is designed with a 50 year. Based on the Haspers method, the discharge at Q50 is 260,055 $\mathrm{m} 3 / \mathrm{s}$.Compared to the amount of flood discharge during the accident (50.15 m3 / s), the collapse of the bridge is not caused by the amount of flood discharge.
\end{abstract}

Keywords: bridge collapse, return period discharge, Kali Sapi River. 


\section{PENDAHULUAN}

Keruntuhan sebuah konstruksi jembatan dapat disebabkan oleh dua faktor yaitu faktor internal dan faktor eksternal. Faktor internal berkaitan dengan struktur bangunan itu sendiri, sedangkan untuk faktor eksternal dapoat disebabkan besaran debit banjir yang melebihi kala ulang rencana. Perencanaan periode ulang (return period atau recurrance interval) suatu banjir rencana pada prinsipnya berlandaskan pada teori kemungkinan lebih, sehingga bila terjadi banjir tertentu melebihi banjir rencana tersebut maka prasarana yang dibangun tidak akan mampu berfungsi seperti yang diharapkan.

Debit kala ulang adalah debit dengan periode ulang tertentu $(\mathrm{T})$ yang diperkirakan akan terjadi berulang pada suatu sungai atau bangunan air. Periode ulang adalah waktu hipotetik di mana suatu kejadian dengan nilai tertentu, debit rencana misalnya, akan disamai atau dilampaui 1 kali dalam jangka waktu hipotetik tersebut. Hal ini tidak berarti bahwa kejadian tersebut akan berulang secara teratur setiap periode ulang tersebut (Kamiana, 2011).
Jembatan Kali Sapi lama selama ini difungsikan sebagai jalan penghubung antara dua desa di Kecamatan Karanganyar Purbalingga. Tahun 2010 jembatan ini mengalami keruntuhan saat terjadi hujan di wilayah tersebut. Besar debit saat itu adalah 50,15 $\mathrm{m}^{3} / \mathrm{dtk}$ dengan curah hujan mencapai 105 mm (PSDA Serayu Citanduy, 2011 dalam Sodikin, dkk, 2017).

\section{METODE PENELITIAN}

Metode penelitian yang digunakan pada tulisan ini adalah dengan mengkaji data sekunder meliputi data hujan dan debit sungai untuk mengetahui besaran debit kala ulang pada sungai tersebut. Besaran kala ulang tersebut selanjutnya dihubungkan dengan kejadian keruntuhan dan umur rencana jembatan untuk mengetahui penyebab keruntuhan.

\subsection{Bahan Penelitian}

\subsubsection{Lokasi Penelitian}

Lokasi penelitian ini mengambil lokasi di Sungai Kali Sapi pada pos pengukuran hujan dan debit di Jembatan Kali Sapi lama.

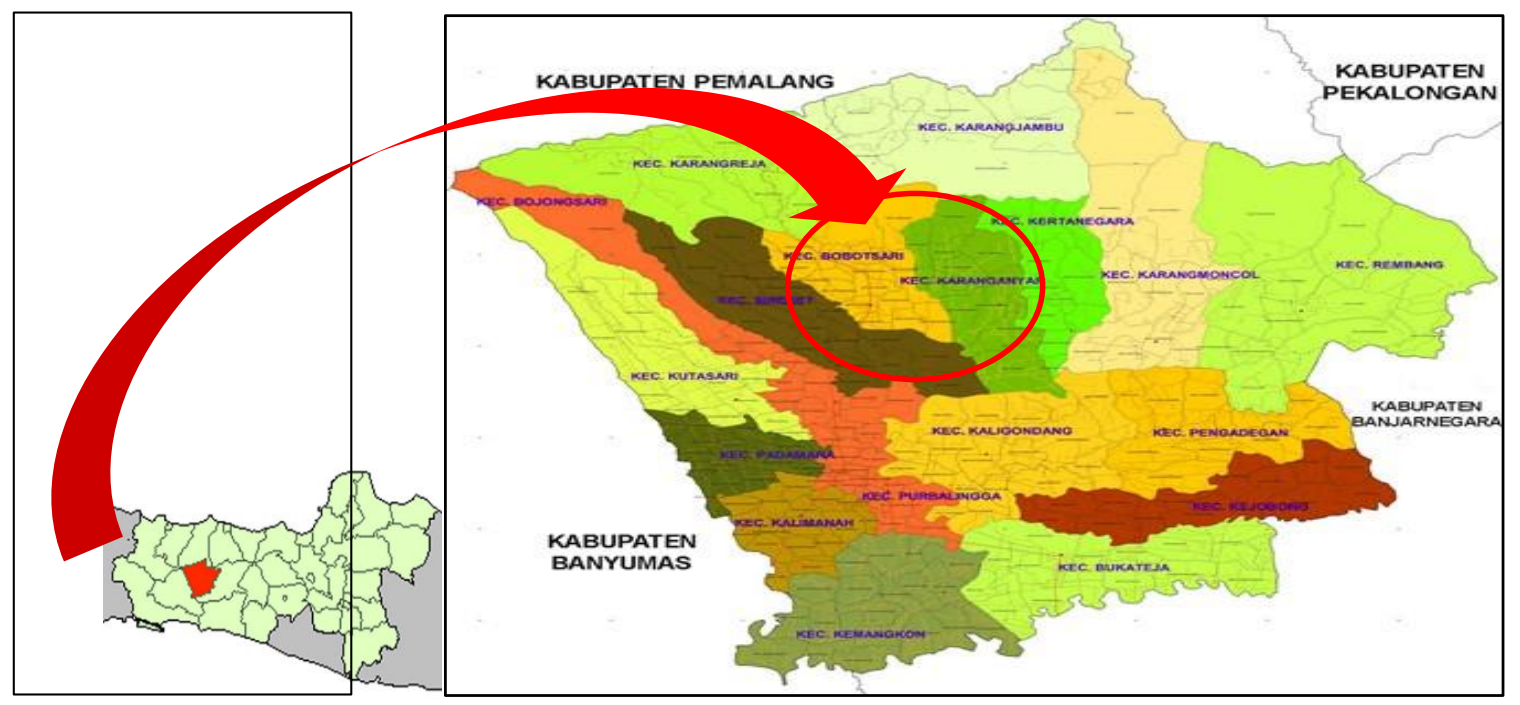

Gambar 1. Peta Lokasi Penelitian

Sumber: Kabupaten Purbalingga dalam Angka, 2016

\subsubsection{Pengumpulan Data}

Data yang digunakan dalan tulisan ini berupa data data luas DAS Sungai Kali Sapi, data hujan dari stasiun hujan di Mandiraja, Bawang dan Karangsambung, serta peta stasiun hujan dimaksud. Data-data tersebut diperoleh dari Balai PSDA Serayu Citanduy dan dinas pekerjaan umum kabupaten banjarnegara. 


\subsection{Metode Penelitian}

\subsubsection{Analisis Data Hidrologi}

Data curah hujan yang diperlukan adalah data curah hujan harian yang tercatat pada stasiun hujan terdekat dan berpengaruh terhadap aliran air pada Daerah Aliran Sungai (DAS) yang bersangkutan. Perhitungan curah hujan rata rata pada penelitian ini menggunakan metode polygon thiessen.

$\overline{\mathrm{R}}=\frac{\mathrm{A}_{1} \mathrm{R}_{1}+\mathrm{A}_{2} \mathrm{R}_{2}+\mathrm{A}_{3} \mathrm{R}_{3} \ldots \ldots . . . A_{\mathrm{n}} \mathrm{R}_{\mathrm{n}}}{\mathrm{A}_{1}+\mathrm{A}_{2}+\ldots+\mathrm{A}_{\mathrm{n}}}$

\subsubsection{Analisis Statistika}

Analisis statistika berkaitan dengan analisis frekuensi kejadiannya melalui penerapan distribusi kemungkinan. Parameter yang digunakan dalam perhitungan analisis frekuensi meliputi parameter nilai rata-rata $(\overline{\mathrm{X}})$, deviasi standar (S), koefisien variasi (Cv), koefisien kemencengan (Cs) dan koefisien kurtosis (Ck) (Soewarno, 1995)..

Standar Deviasi (Standard Deviation) :

$\mathrm{S}=\sqrt{\frac{\sum(\mathrm{Xi}-\overline{\mathrm{X}})^{2}}{\mathrm{n}-1}}$

Koefisien Variasi (Variation) :

$C v=\frac{S}{\bar{X}}$

Koefisien Kemencengan (Skewness) :

$C S=\frac{\sum_{i=1}^{n}(X i-\bar{X})^{3}}{(n-1)(n-2) S^{3}}$

Koefisien Kurtosis (Curtosis) :

$C k=\frac{n^{2} \cdot \Sigma(X i-\bar{X})^{4}}{(n-1)(n-2)(n-3) S^{4}}$

Jenis-jenis distribusi yang digunakan dalam penelitian ini meliputi :

1. Distribusi probabilitas Gumbel

2. Distribusi probabilitas Log Normal

3. Distribusi probabilitas Log Pearson III

\subsubsection{Uji Kecocokan Distribusi}

Uji kecocokan (goodness of fit test) dimaksudkan untuk menentukan seberapa baik kecocokan antara frekuensi yang diobservasi dari peristiwa pada sebuah sampel dan frekuensi harapan yang diperoleh dari distribusi yang dihipotesiskan. Kualitas dari pengujian yang cocok antara frekuensi yang diobservasi dan diharapkan berdasar pada kuantitas uji chikuadrat (M. M. Rashid, S. B. Faruque, J.B. Alam, 2012).

Ada dua jenis uji kecocokan (Goodness of fit test) yaitu uji kecocokan Chi-Square dan SmirnovKolmogorof. Umumnya pengujian dilaksanakan dengan cara mengambarkan data pada kertas peluang dan menentukan apakah data tersebut merupakan garis lurus, atau dengan membandingkan kurva frekuensi dari data pengamatan terhadap kurva frekuensi teoritisnya (Soewarno, 1995; Soemarto, 1999; Sharon dkk, 2014).

\subsubsection{Debit Banjir Kala Ulang}

Metoda-metoda perhitungan debit banjir kala ulang sangat bergantung pada cara pendekatannya pada alam sebagai pengejawantahan dari sistem penalaran yang diterapkan pada faktor-faktor alam atau parameter-parameter fisik dalam menentukan pola matematik dari sistem operasi (J. Loebis, 1987). Dalam penelitian ini, metoda perhitungan debit banjir kala ulang dilakukan pada 3 debit kala ulang yaitu pada $Q_{25}, Q_{50}$, dan $Q_{100}$ menggunakan 3 metode yaitu metode Haspers, Weduwen dan Melchior seperti berikut (Kamiana, 2011; Sriyono, 2012; Isri, 2016; Marcelia, 2014).

a. Metode haspers

$\mathrm{Q}=\alpha \cdot \beta . \mathrm{I} \cdot \mathrm{A}$

Metode weduwen

$Q_{\text {maks jkrta }}=\alpha \cdot \beta \cdot \mathrm{I} \cdot \mathrm{A}$

Metode melchior

$\mathrm{Q}_{\mathrm{maks}}=\alpha \cdot \mathrm{I} \cdot \mathrm{A}$

\subsection{Langkah-langkah Penelitian}




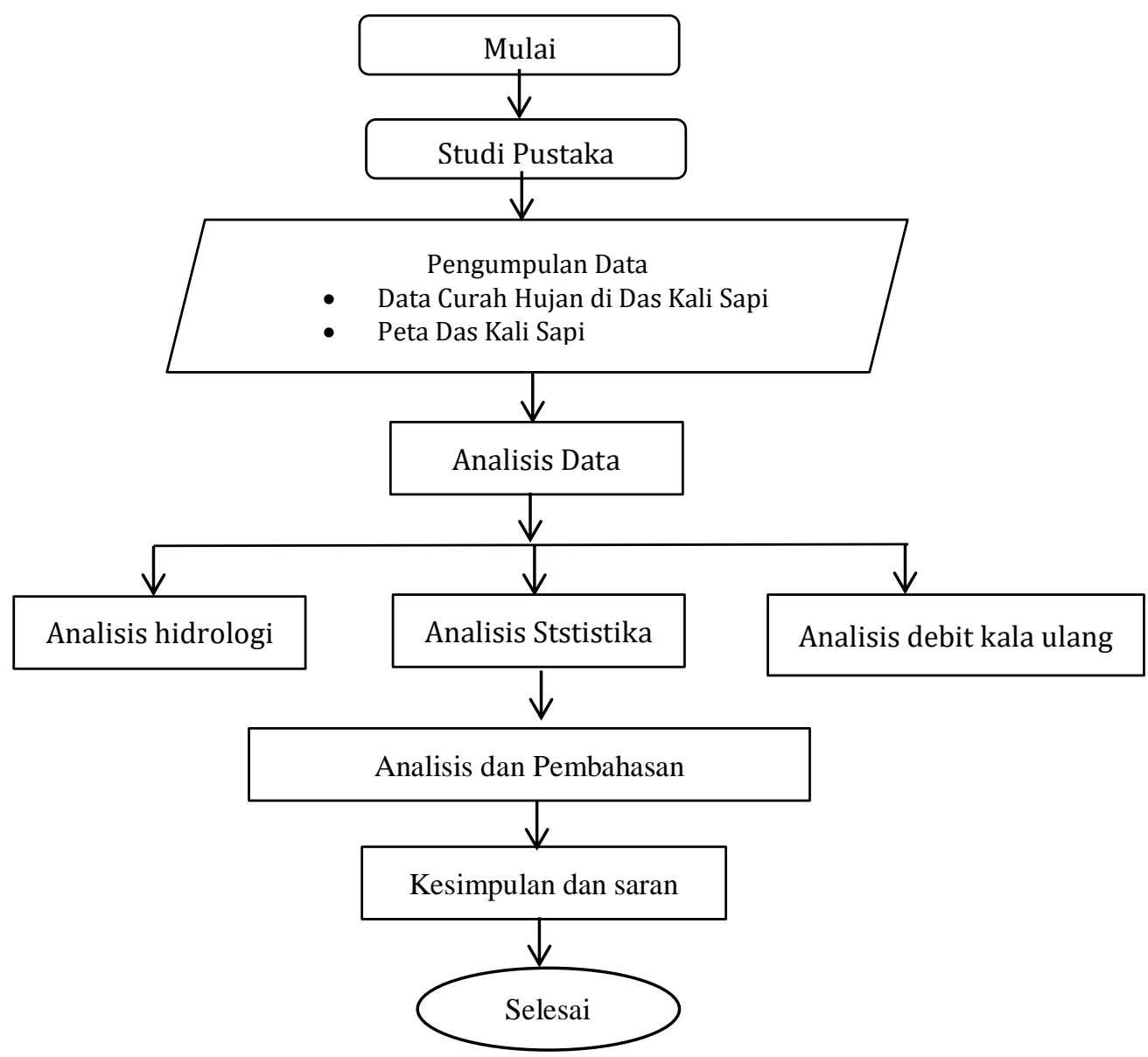

Gambar 2. Langkah-langkah Pelaksanaan Penelitian

\subsection{Analisis dan Pembahasan Hasil}

Analisis dan pembahasan hasi berupa analisis untuk menentukan besaran debit banjir kala ulang pada Sungai Kalisapi. Besaran debit kala ulang ditentukan menggunakan 3 nilai kala ulang, yaitu $Q_{25}, Q_{50}$, dan $Q_{100}$ menggunakan 3 metode yaitu metode Haspers, Weduwen dan
Melchior. Debit kala ulang hasil analisis kemudian dihubungkan dengan besaran debit ketika terjadi keruntuhan jembatan Kali Sapi.

\section{HASIL DAN PEMBAHASAN}

\subsection{Analisis curah hujan}




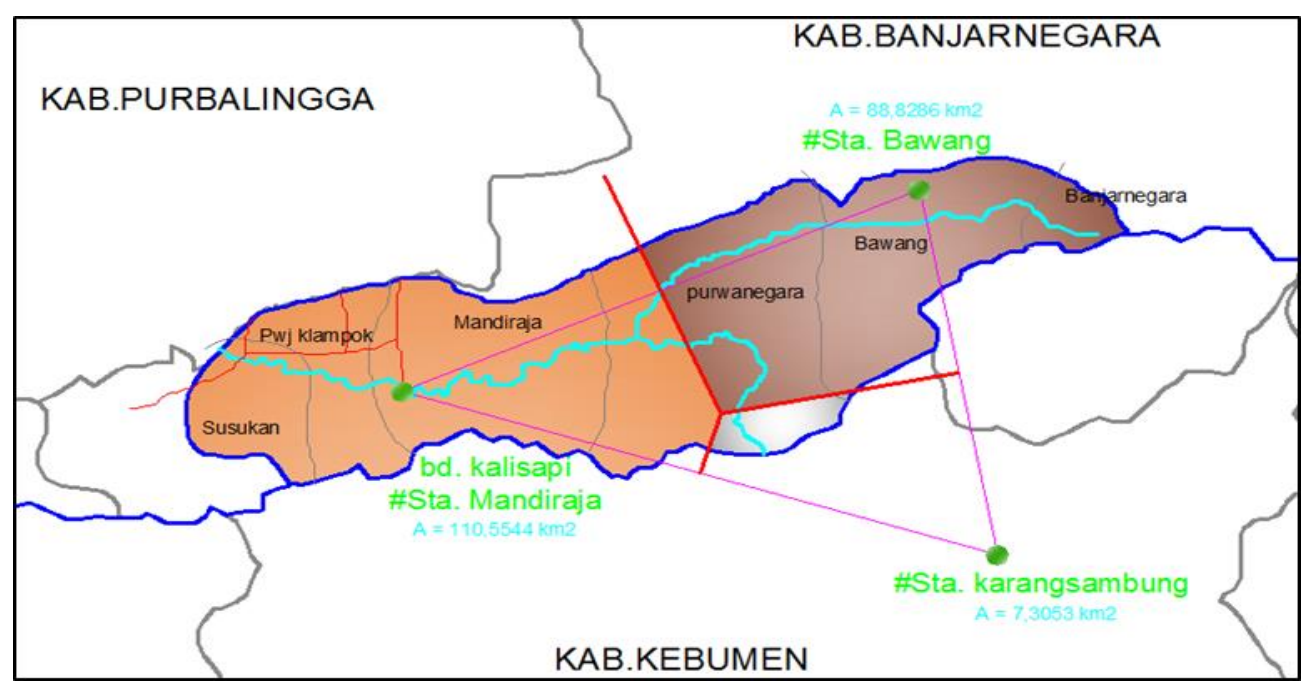

Gambar 3. DAS Kalisapi dan Poligon Thiessen

Hasil perhitungan curah hujan rata rata

dari stasiun Bawang, Mandiraja dan Karangsambung ditunjukkan pada Tabel 1.

Tabel 1. Curah Hujan Harian Rata rata

\begin{tabular}{|c|c|c|c|c|c|c|c|c|}
\hline \multirow{3}{*}{ No } & \multirow{3}{*}{ Tahun } & \multirow{2}{*}{\multicolumn{2}{|c|}{$\begin{array}{c}\text { Mandiraja } \\
0,534884655\end{array}$}} & \multirow{2}{*}{\multicolumn{2}{|c|}{$\begin{array}{c}\text { Bawang } \\
0,429770819\end{array}$}} & \multirow{2}{*}{\multicolumn{2}{|c|}{$\begin{array}{c}\text { Karang sambung } \\
0,035344526 \\
\end{array}$}} & \multirow{3}{*}{$\begin{array}{c}\text { Harian } \\
\text { Rata-rata } \\
\text { mm }\end{array}$} \\
\hline & & & & & & & & \\
\hline & & RI & CRI & RI & CRI & RI & CRI & \\
\hline 1 & 2007 & 75 & 40,116 & 71,222 & 30,609 & 180,220 & 6,370 & 77,095 \\
\hline 2 & 2008 & 85 & 45,465 & 74,938 & 32,206 & 177,290 & 6,266 & 83,937 \\
\hline 3 & 2009 & 86 & 46,000 & 80,512 & 34,602 & 100 & 3,534 & 84,136 \\
\hline 4 & 2010 & 128 & 68,465 & 135,012 & 58,024 & 173 & 6,115 & 132,604 \\
\hline 5 & 2011 & 110 & 58,837 & 154,830 & 66,541 & 116 & 4,100 & 129,479 \\
\hline 6 & 2012 & 108 & 57,768 & 142,444 & 61,218 & 134 & 4,736 & 123,722 \\
\hline 7 & 2013 & 116 & 62,047 & 81 & 34,811 & 143 & 5,054 & 101,912 \\
\hline 8 & 2014 & 102 & 54,558 & 109 & 46,845 & 160 & 5,655 & 107,058 \\
\hline 9 & 2015 & 94 & 50,279 & 67 & 28,795 & 124 & 4,383 & 83,457 \\
\hline 10 & 2016 & 108 & 57,768 & 82 & 35,241 & 239 & 8,447 & 101,456 \\
\hline & & & & & & & & 102,486 \\
\hline
\end{tabular}

\subsection{Parameter Statistik}

Parameter statisik data curah hujan yang perlu diperkirakan untuk pemilihan distribusi yang sesuai dengan sebaran data. Besarnya parameter nilai, dapat diukur yakni melalui perhitungan parameter statistik untuk mencari
$(\mathrm{Xi}-\mathrm{X}),(\mathrm{Xi}-\mathrm{X})^{2},(\mathrm{Xi}-\mathrm{X})^{3},(\mathrm{Xi}-\mathrm{X})^{4}$ sebagaimana dapat dilihat pada Tabel 2.

dengan :

$$
\begin{aligned}
X i & =\text { besarnya curah hujan maksimum }(\mathrm{mm}) \\
X & =\text { rata-rata curah hujan maksimum }(\mathrm{mm})
\end{aligned}
$$


Tabel 2. Parameter Statistik Data Curah Hujan

\begin{tabular}{cccccc}
\hline Tahun & $\mathrm{X}$ & $(\mathrm{Xi}-\mathrm{Xr})$ & $(\mathrm{Xi}-\mathrm{Xr}) 2$ & $(\mathrm{Xi}-\mathrm{Xr}) 3$ & $(\mathrm{Xi}-\mathrm{Xr}) 4$ \\
\hline 2007 & 77,095 & $-25,390$ & 644,675 & $-16368,582$ & 415605,636 \\
2015 & 83,457 & $-19,029$ & 362,108 & $-6890,609$ & 131122,379 \\
2008 & 83,937 & $-18,548$ & 344,035 & $-6381,223$ & 118360,077 \\
2009 & 84,136 & $-18,350$ & 336,707 & $-6178,433$ & 113371,648 \\
2016 & 101,456 & $-1,030$ & 1,060 & $-1,091$ & 1,124 \\
2013 & 101,912 & $-0,573$ & 0,329 & $-0,188$ & 0,108 \\
2014 & 107,058 & 4,573 & 20,910 & 95,614 & 437,216 \\
2012 & 123,722 & 21,236 & 450,975 & 9576,989 & 203378,616 \\
2011 & 129,479 & 26,993 & 728,625 & 19667,826 & 530894,812 \\
2010 & 132,604 & 30,118 & 907,113 & 27320,716 & 822853,961 \\
$\sum$ & 1024,857 & 0,000 & 3796,537 & 20841,017 & 2336025,576 \\
\hline
\end{tabular}

Berdasarkani perhitungan parameter statistik didapatkan dari persamaan (1) $S=$ 20,538, pers (2) $\mathrm{Cv}=0,200$, pers (3) $\mathrm{Cs}=0,334 \mathrm{dan}$ pers (4) $\mathrm{Ck}=2,604$. Berdasarkan perhitungan diatas didapat nilai $\mathrm{Cs}=0,565$ Dan nilai $\mathrm{Ck}=$
4,080. Hasil perhitungan curah hujan rencana dengan 4 (empat) distribusi Gumbel, Log Person, Normal ,dan Log Normal ditunjukkan pada Tabel 3.

Tabel 3. Hasil Perhitungan Curah Hujan Rencana

\begin{tabular}{cccc}
\hline $\mathrm{T}$ & \multicolumn{3}{c}{ Rt (mm) } \\
\cline { 2 - 4 } (Tahun) & Gumbel & Log normal & Log Pearson Tipe III \\
\hline 25 & 160,955 & 141,304 & 144,711 \\
50 & 176,168 & 158,967 & 154,850 \\
100 & 191,270 & 173,344 & 164,768 \\
\hline
\end{tabular}

\subsection{Analisis Kesesuaian Distribusi Curah Hujan}

Analisis Kesesuaian Distribusi Curah Hujan berguna untuk memperkuat perkiraan distribusi yang digunakan sudah sesuai. Berdasarkan hasil uji kesesuaian distribusi menggunakan uji chi-kuadrat dan uji smirnovkolmogorov, dapat dilihat pada Tabel 4.

Tabel 4. Hasil Uji Distribusi Statistik

\begin{tabular}{ccccc}
\hline No & Jenis Distribusi & syarat & Hasil Hitungan & Kesimpulan \\
\hline \multirow{2}{*}{1} & Normal & $\mathrm{Cs} \approx 0$ & $\mathrm{Cs}=0,334$ & Tidak memenuhi \\
2 & Log Normal & $\mathrm{Ck} \approx 0$ & $\mathrm{Ck}=2,604$ & Tidak memenuhi \\
3 & Log Person III & $3 \mathrm{Cv}+\mathrm{Cv} 3 \approx 1,2497$ & $\mathrm{Cs}=0,334$ & Memenuhi \\
4 & Gumbel & $\mathrm{Cs} \neq 0$ & $\mathrm{Cs}=0,334$ & Memenuhi \\
\hline
\end{tabular}

Mengacu Tabel 4, distribusi yang dapat digunakan dalam perhitungan curah hujan rencana adalah Distribusi Gumbel dengan nilai Cs $=0,334$ mendekati syarat $\mathrm{Cs} \leq 1,1396$ dan $\mathrm{Ck}=$ 2,604 mendekati syarat $\mathrm{Ck} \leq 5,4002$.

3.4 Analisis debit banjir kala ulang
Perhitungan debit banjir kala ulang dilakukan dengan rumus persamaan (6) Haspers,(7) Weduwen dan (8) Melchior. Hasil perhitungan curah hujan rencana dengan kala ulang 25, 50 dan 100 tahun dengan metode Gumbel (Tabel 3) maka didapat hasil perhitungan 
intensitas curah hujan sebagaimana dapat dilihat pada Tabel 5 .

Tabel 5. Debit Banjir Kala Ulang

\begin{tabular}{cccc}
\hline Kala & \multicolumn{3}{c}{ Metode perhitungan Q $(\mathrm{m} 3 / \mathrm{dtk})$} \\
\cline { 2 - 4 } Ulang & Weduwen & Haspers & Melchior \\
\hline Q25 & 274,520 & 237,597 & 304,837 \\
Q50 & 300,468 & 260,055 & 333,651 \\
Q100 & 326,225 & 282,347 & 362,251 \\
\hline
\end{tabular}

\subsection{Analisis dan Pembahasan}

Mengacu data perencanaan jembatan, umur rencana Jembatan Kalisapi dibangun untuk rencana 50 tahun. Berdasarkan analisis Metode Haspers, Weduwen dan Melchior, debit kala ulang terkecil untuk kala ulang 50 tahun adalah 260,055 m3/detik. Dengan memperhatikan besaran debit saat kejadian keruntuhan jembatan Kalisapi sebesar 50,15 m³ $/$ detik, maka debit sebesar $50,15 \mathrm{~m}^{3} /$ detik pada saat terjadi keruntuhan, bukan merupakan faktor utama penyebab terjadi runtuhnya jembatan kali Sapi.

\section{DAFTAR PUSTAKA}

Anonim. (2016). Kabupaten Purbalingga dalam Angka 2016, Peta Kabupaten Purbalingga

Soemarto, C.D. (1999). Hidrologi Teknik. Jakarta: Erlangga.

Kamiana, I, M. 2011. Teknik Perhitungan Debit Rencana Bangunan Air. Yogyakarta : Graha Ilmu.

Loebis, J. (1987). Banjir Rencana Untuk Bangunan Air. Jakarta: Departemen Pekerjaan Umum, Badan Penerbit Pekerjaan Umum.

Rashid, M.M. Faruque, S. B. Alam, J.B. (2012). Modeling of Short Duration rainfall Intensity Duration Frequency (SDR-IDF) Equation for Sylhet City in Bangladesh. ARPN Journal of Science and Technology.

\section{KESIMPULAN}

Berdasarkan hasil analisis, besaran debit terkecil untuk Q50 adalah 260,055 m3/dtk, besaran debit saat terjadi keruntuhan jembatan adalah sebesar 50,15 m3/dtk. Dengan kondisi tersebut, kejadian keruntuhan Jembatan Kalisapi bukan disebabkan oleh debit yang terjadi saat keruntuhan.

\section{UCAPAN TERIMAKASIH}

Penulis mengucapkan terimakasih kepada Kepala Dinas PSDA Serayu Citanduy yang telah meminjamkan data.

Marcelia, (2014). Ketelitian Metode Empiris Untuk Menghitung Debit Banjir Rancangan di Das Bangga. Jurnal Infrastruktur, 4.

Isri, S. (2016). Analisis Debit Banjir Sungai Molompar Kabupaten Minahasa Tenggara, Jurnal Sipil Statik, 4(2), 123-133.

Sharon dkk, (2014). Analisis Debit Banjir Sungai Tondano Menggunakan Metode HSS Gama I dan HSS Limantara. Jurnal Sipil Statik, $4(1)$.

Soewarno. (1995). Hidrologi Aplikasi Metode Statistik Untuk Analisa Data, Nova, Bandung.

Sriyono. (2012). Analisis debit banjir rancangan rehabilitasi situ sidomukti, Jurnal Teknik, 2(2).

Sodikin, W. Marhendi, T. dan Azizi, A. (2017) Analisis Debit Banjir kala Ulang Kalisapi, Tugas Akhir, UMP 